\title{
Study of the Flocculated Particles Sedimentation Assisted by Microcomputer
}

\author{
D. Benouali ${ }^{1}$, S. Kacha ${ }^{2} *$, S. Kherici ${ }^{1}$ and N. Benabadji ${ }^{3}$ \\ ${ }^{I}$ Département de chimie, USTOran, BP 1505, EL-Mnaouer Oran (Algeria) \\ ${ }^{2}$ Laboratoire des Matériaux et systèmes Réactifs (LMSR), Université de Sidi-bel-Abbes (Algeria) \\ ${ }^{3}$ Département de physique, USTOran, BP 1505,El-Mnaouer Oran (Algeria)
}

\begin{abstract}
Sludge known as waste products, collected during various stages of water treatment, are fluids containing suspended solid particles in water. Sedimentation velocity of these particles is generally determined using batch settling tests. This velocity is a determining parameter in dimensioning and controlling the thickeners. Realization and contribution to the automation of a simple tool for such tests is the subject of this work. The used column (H: $2.30 \mathrm{~m}, \mathrm{D}: 0.20 \mathrm{~m})$ was provided with infra-red sensors, to quantify the total suspended solid particles (TSS) in water. The automated experimental device avoids the recourse to the slow and limited conventional gravimetric method. The study of the settled particles becomes faster and furthermore by automation of the TSS measurements, it is possible to carry out the data acquisition directly on PC via an adequate interface.
\end{abstract}

Key Words: Suspended particles, Sedimentation velocity, flocculation, Infra-red sensors, Data acquisition.

\section{INTRODUCTION}

The water treatment and purification process generates sludge, which is made up of inorganic and organic compounds that are soluble or colloidal, agglomerated by addition of coagulants and flocculating agents. The flocculated sludge sedimentation is not a simple operation to model and cannot substitute the experimental batch-settling tests [1]. However, several recent works [2-4] suggest many formulas which need experimental data for their checking. This because, the experimental study of the sludge sedimentation using static or dynamic settling tests must provide all the essential data. Thus a large number of data, carried out by on-line measurements, is required to correct the mathematical models in this field. For the automation of the batch settling tests, the major problem is the on-line measurement device [5]. In practice, according to Wren [6], the characteristics of the suspended particles in water can be quantified by optical methods using transmission and back-scattering of the visible, the infra-red or the laser radiations.

At the moment, the development of such sensors interests many researchers. For example, the infra-red sensor was described and used for the characterization of activated sludge, by Urrutlkoetxea and Garcia-Heras, since 1993 [7]. Nowadays, these sensors are used, in real applications, for the development of the data acquisition system and control of the sedimentation process [8-10]. But, the fooling of the sensor during the measurements remains a true obstacle $[11,12]$. This work proposes some discussion about producing an infra-red sensor and a data acquisition chain able to

*Address correspondence to this author at the Laboratoire des Matériaux et systèmes Réactifs (LMSR), Université de Sidi-bel-Abbes (Algeria); Fax: +2134854 4344 ; E-mail: smail_k@yahoo.fr provide a large number of variables concerning the TSS evolution, according to the column depth and time.

\section{MATERIALS AND METHODS}

\subsection{Batch Settling Tests Device}

The general diagram of the batch settling tests devise, used in this work, is presented in Fig. (1).

The column is made of PVC and has the following dimensions: height $2.30 \mathrm{~m}$ and diameter $0.20 \mathrm{~m}$. To carry out water sampling at each level, the column is equipped by three valves superimposed, $0.60 \mathrm{~m}$ apart, and three infra-red sensors (Fig. 2). The infra-red captor is able to give an analogical signal allowing the quantification of TSS, according to the time and depth. This system can describe correctly the flocculated particles sedimentation, by the acquisition of the analogical signal, communicated to the PC, via a multimeter MAS-34 at exit $R S 232$. The software which ensures the acquisition (DDM view version 2 ) is commercialised with the multimeter. It is known that the turbidity of water is in relationship with the amount of TSS, thus the amount of suspended solid particles contained in water, can be deduced by measurements of the infra-red light quantity, transmitted and back-scattered by the particles. The data acquisition of turbidity was carried out using a simple device, made in the laboratory. It consists of two infra-red led, the first is a transmitting led, while the second is a receiving led (Fig. 2). The infra-red emitter $(940 \mathrm{~nm})$ is connected to an AC power source $220 \mathrm{~V}$ converted to a DC $12 \mathrm{~V}$.

\subsection{Flocculated Sludge for the Batch Tests}

The sludge used in this work was prepared using Sarno dam surface water in Sidi bel-Abbès, Algeria, by applying the same procedure of treatment clarification used in the dam 


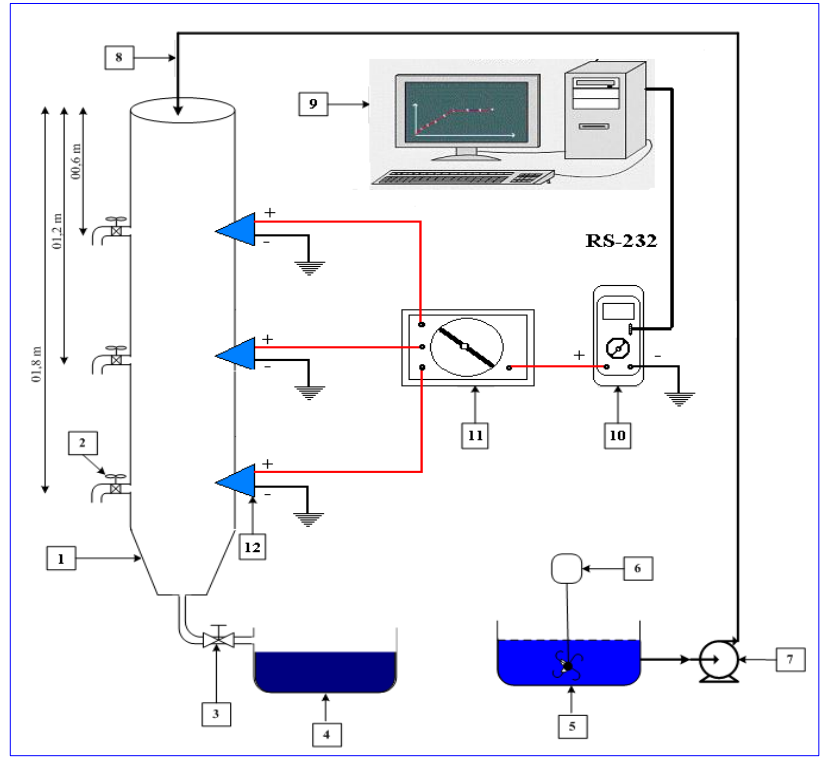

1- The settling column
2- Valves of sampling
3- Stop Valve
4- Vat of recovery
5- Vat of agitation
6- Agitator

8- Pipeline

9- PC

10- Multimeter

11- Switch

12- Infra-red Sensor

7- Circulating/repression pump

Fig. (1). Diagram of the laboratory pilot device for the batch settling tests.

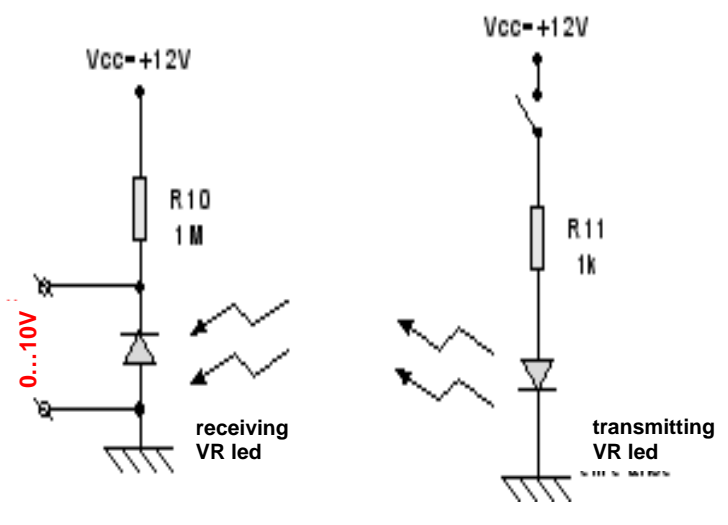

Fig. (2). Diagram of the infra-red Transmitting/Receiving couple

station treatment. The physicochemical characteristics of the dam raw water are presented in Table 1. The treatment comprises a preliminary stage, which consists to add a powder activated carbon (PAC), followed by a coagulationflocculation stage using a solid form of both aluminum sulphate $\left[\mathrm{Al}_{2}\left(\mathrm{SO}_{4}\right)_{3} \cdot 6 \mathrm{H}_{2} \mathrm{O}\right]$ as a coagulant, and a polyelectrolyte (Acrylamide) as a flocculating agent. The reagents were added to the water as they were provided in their solid form. In order to determine the optimal concentrations of the three reagents, the batch tests were carried out in a laboratory flocculator, by the Jar-tests method. Different amounts of reagents in the range of 0-70 $\mathrm{mg} / \mathrm{L}$ (PAC, coagulant and floccu- lating agent) were added to $1 \mathrm{~L}$ of dam raw water. After the determination of the optimal amount of PAC, the coagulant was added to the water initially agitated vigorously at 200 rpm during two minutes, and then the agitation was reduced to $60 \mathrm{rpm}$ for $15 \mathrm{~min}$ during the addition of the polyelectrolyte. Water thus treated was decanted for $15 \mathrm{~min}$ and then the $\mathrm{pH}$, the turbidity and the oxydability with the permanganate test called permanganate index (PI) of the clarified water were determined.

The $\mathrm{pH}$ was measured using a $\mathrm{pH}$-meter (InoLab $\mathrm{pH}$ Level 1, D-82362 Weillheim, Germany). The turbidity was measured using a turbidimeter (HANNA Instruments, LP2000, Hungary). The dissolved organic matter quantities were estimated by the PI method according to Analyse de l'eau [13]. The optimal amounts of reagents were determined after consulting the results of analysis and the size of the formed flocs. Once these amounts (determined for $1 \mathrm{~L}$ of water) were made, the calculation of the corresponding quantities for the production of a more significant volume of sludge was carried out.

\subsection{Batch Settling Tests}

The batch settling tests were done to determine the percentage of solid particles eliminated at each column level, at different time intervals. The tests were carried out on dam water sample, in a flask of $50 \mathrm{~L}$, treated as indicated above. While the column valves were kept closed, the sludge was transferred by the top of the column until filling (Fig. 1). To standardize the tests, the data acquisition started 15 seconds after the injection of the suspension. 
Table 1. Average Values of the Main Physicochemical Parameters of Sarno Dam Raw Water (Algeria)

\begin{tabular}{|c|c|}
\hline Concentration (mg/L) & Parameters \\
\hline 62 & $\mathrm{Ca}^{2+}$ \\
\hline 52 & $\mathrm{Mg}^{2+}$ \\
\hline 115 & $\mathrm{Na}^{+}$ \\
\hline 4 & $\mathrm{~K}^{+}$ \\
\hline 230 & $\mathrm{Cl}^{-}$ \\
\hline 170 & $\mathrm{SO}_{4}{ }^{2-}$ \\
\hline 146 & $\mathrm{CO}_{3} \mathrm{H}^{-}$ \\
\hline 4 & $\mathrm{NO}_{3}^{-}$ \\
\hline 0.09 & $\mathrm{NO}^{2-}$ \\
\hline 719 & Mineralization \\
\hline 760 & RS à $110^{\circ} \mathrm{C}$ \\
\hline 0.1 & Phosphor \\
\hline 50 & COD \\
\hline 13.3 & $\mathrm{BOD}_{5}$ \\
\hline 5.17 & TOC \\
\hline 37 & $\mathrm{TH}\left({ }^{\circ} \mathrm{F}\right)$ \\
\hline $10.5-12$ & $\mathrm{CTA}\left({ }^{\circ} \mathrm{F}\right)$ \\
\hline 20.5 & Turbidity (NTU) \\
\hline 1160 & Conductivity $25(\mu \mathrm{S} / \mathrm{cm})$ \\
\hline 7.9 & $\mathrm{pH}$ \\
\hline
\end{tabular}

\section{RESULTS AND DISCUSSION}

\subsection{Determination of the Optimum Conditions for Sludge Preparation.}

\subsubsection{Effect of Reagents Dose on pH of Water}

The preparation of good quality of sludge is a very important stage in the study of the behavior of the flocculated particles in the settling column. When the suspended particles are agglomerated under better conditions in structured flocs, the decantation of sludge becomes easier to carry out. In order to determine the optimal amounts of treatment reagents, the influence of their concentration on the $\mathrm{pH}$, turbidity and organic matter removal was investigated.

The effect of reagents concentration was studied in the range of $0-70 \mathrm{mg} / \mathrm{L}$. The Fig. (3) shows that when increasing amounts of PAC were added, the $\mathrm{pH}$ of water remains almost constant and it stabilize near $\mathrm{pH} 8$. On the other hand, the addition of the coagulant influences, considerably the $\mathrm{pH}$ of water. In aqueous solution, aluminum sulphate reacts as a Lewis acid, which releases hydrolysable $\mathrm{Al}^{3+}$ cations, and gives a series of monomeric species of $\mathrm{Al}$, such as $\mathrm{Al}(\mathrm{OH})^{2+}$ $\mathrm{Al}(\mathrm{OH})_{2}{ }^{+} \mathrm{Al}(\mathrm{OH})^{4-}$ or polymeric species such as $\mathrm{Al}_{13} \mathrm{O}_{4}(\mathrm{OH})_{24}{ }^{7+}$ as shown in a recent study of Kacha et al.,

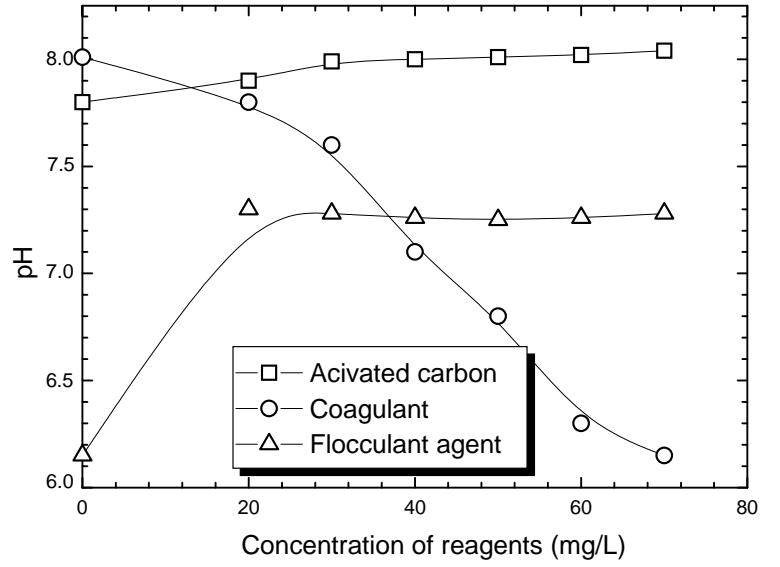

Fig. (3). Optimal conditions for preparation of the sludge. Influence of the reagents concentration on the $\mathrm{pH}$ of water.

Volume of sample : $1 \mathrm{~L}$; Temperature : $20 \pm 1{ }^{\circ} \mathrm{C}$

(2003) [14]. The presence of one or several of these species is strongly dependent on the $\mathrm{pH}$ value of water. It was noticed that the addition of $70 \mathrm{mg} / \mathrm{L}$ of coagulant varies the $\mathrm{pH}$ of water from $\mathrm{pH} 8.0$ to $\mathrm{pH} 6.1$. However, the addition of the polyelectrolyte has a stabilizing effect on the $\mathrm{pH}$ of water. After the first few added amounts, the $\mathrm{pH}$ increases from 6.0 to reach 7.2 and remains constant in spite of increasing amounts of polyelectrolyte.

\subsubsection{Effect of Reagents Dose on Turbidity of Water}

The Fig. (4) shows that the three reagents have a different effect on the turbidity of water. When PAC is added, the turbidity first decreases from 2.1 NTU until minimal value of 1.5 NTU; after this point, each further increasing in the PAC dose causes a dramatically increasing in the turbidity to reach 3.7 at $70 \mathrm{mg} / \mathrm{L}$ (Fig. 4). The activated carbon known as an adsorbent can fix certain chemical aqueous species, thus the turbidity of water decreases, but when the amounts of PAC become excessive the turbidity increases. The coagulant effect was opposite to that of PAC. The turbidity increases indicating a stabilization of the suspension, then after a peak point at $30 \mathrm{mg} / \mathrm{L}$, it decreases indicating the destabilization of the colloids suspension. At the optimal coagulant concentration (OCC), the turbidity of water reaches its minimal value $0.35 \mathrm{NTU}$. The addition of flocculent does not affect the value of turbidity and its role is limited to the flocculation of agglomerated particles.

\subsubsection{Effect of Reagents Dose on PI of Water}

The measurements of the permanganate index (PI) give an appreciable quantification of the organic matter in water. It is often desirable to eliminate these matters from water to allow them to pass to the formed sludge. The Fig. (5) indicates that the addition of $30 \mathrm{mg} / \mathrm{L}$ of PAC can decrease the PI from $17.2 \mathrm{mg} / \mathrm{L}$ to $7.4 \mathrm{mg} / \mathrm{L}$, but each further addition had an opposite effect. The coagulant had a direct effect on PI elimination, and it decreases with croissant amounts of coagulant. The PI passes from $7.4 \mathrm{mg} / \mathrm{L}$ (value after PAC addition) to $0.3 \mathrm{mg} / \mathrm{L}$ by $70 \mathrm{mg} / \mathrm{L}$ of coagulant. As observed in case of turbidity, the addition of the flocculent agent does not affect the PI value. 


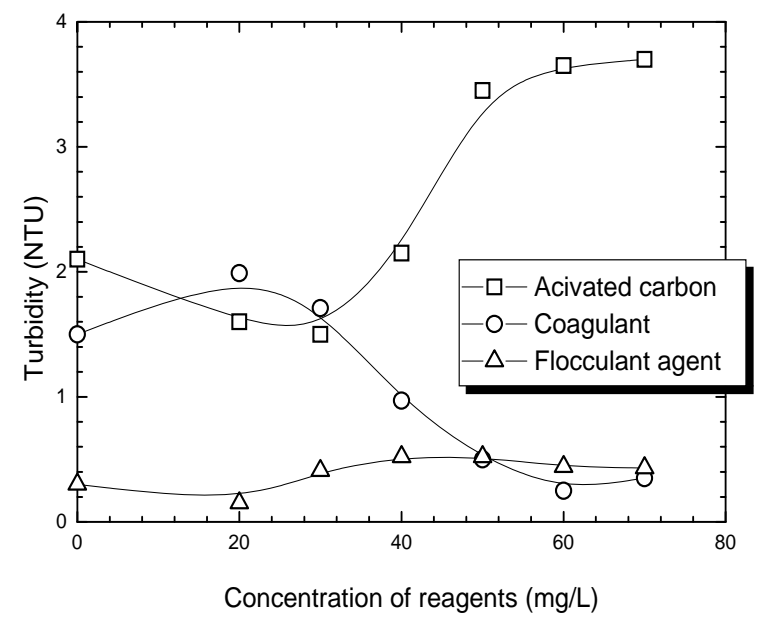

Fig. (4). Optimal conditions for preparation of the sludge. Influence of the reagents concentration on the turbidity of water.

Volume of sample : $1 \mathrm{~L}$; Temperature : $20 \pm 1{ }^{\circ} \mathrm{C}$

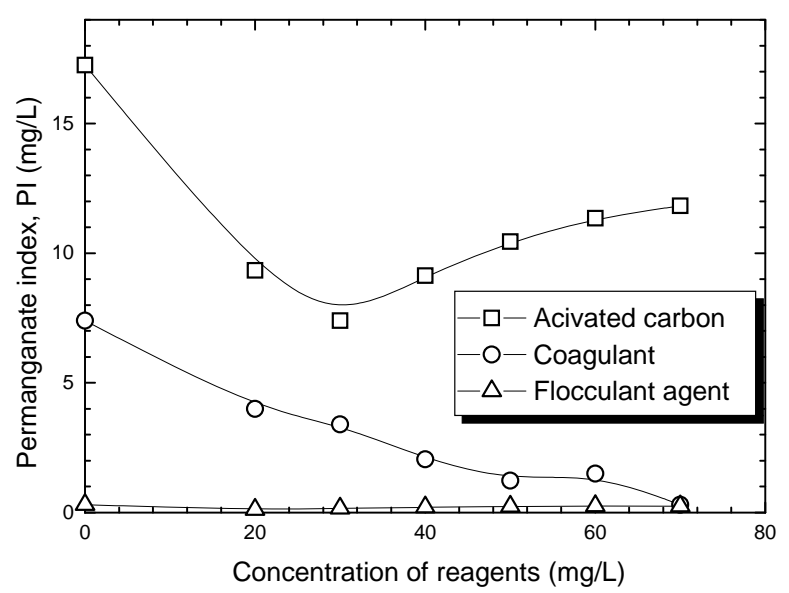

Fig. (5). Optimal conditions for preparation of the sludge. Influence of the reagents concentration on the PI of water.

Volume of sample : $1 \mathrm{~L}$; Temperature : $20 \pm 1{ }^{\circ} \mathrm{C}$

Finally, from the Figs. (3-5) it is seen that PAC and the coagulant are the two reagents directly affecting the water parameters in the clarification process. Thus, the optimal amounts of reagents required for a good preparation of the batch settling tests, are: $30 \mathrm{mg} / \mathrm{L}$ of PAC, $60 \mathrm{mg} / \mathrm{L}$ of coagulant and $30 \mathrm{mg} / \mathrm{L}$ of flocculent.

\subsection{Data Acquisition}

\subsubsection{Calibration of the Tests}

The monitoring of the TSS variations in the column, at various times and variable levels $(0.60,1.20$, and $1.80 \mathrm{~m})$, was investigated. In order to calibrate the settling device, three samples were taken at the same level in three different times, and then the TSS values were measured using the conventional gravimetric method, by filtration. The effectiveness of the calibration was checked separately using a small-scale settling device. It is a small column of $0.40 \mathrm{~m}$ height and $0.20 \mathrm{~m}$ diameter, equipped by two diodes, transmitting on the one hand, and a receiving diode, on the other hand, perpendicularly placed to the emitted beam direction. The effect of the infra-red transmitting source on the TSS quantification was thus tested using this small-scale model. Moreover, the behavior of the receiving diode has been tested.

\subsubsection{Effect of the Level in the Column on the Flocculated Particles Sedimentation}

The results of the settling measurements and the behavior of the suspended particles according to their level in the column were examined. After several treatments, it can be seen three profiles of the flocculated particles sedimentation (Fig. 6). Each profile indicates the sedimentation velocity of the particle according to its environment and its free movement space. The particles that situated in the top of the column have a high free movement space witch allow them to acquire a high sedimentation velocity. As a result of this, the turbidity of water decreases quickly (profile 1). As the particles approach the bottom of the column, their sedimentation velocity decreases because of their bringing together, which causes a reduction in their precipitation movement, thus the sedimentation becomes constrained. This behavior of the flocculated particles in the column is described by the variation of the turbidity of water at each level (profiles 2 and 3 ).

\subsubsection{Batch Settling Data Acquisition}

The acquisition of the results is obtained in the form of Excel CSV file as indicated in 'Materials and Methods' section. The results represent three instantaneous values collected by the three infra-red diodes separated by a reference value of $11.84 \mathrm{~V}$ (Fig. 6). This mode of acquisition is controlled by a simple electronic switch realized by the integrated circuits CD4051 and CD4060. In addition, the return to the referential value of $11.84 \mathrm{~V}$ allows the possibility to correct the received signal by the sensors if the feed tension is not sufficiently stable. Using this experimental device, it is possible to instantaneously obtain, with success, the curves which represent the TSS variations in terms of time and depths in the column. Thus, the weight percentage of the eliminated particles, the average yield according to time, isoconcentrations curves, and consequently, the sedimentation velocity of flocculated particles can be determined with high degree of accuracy.

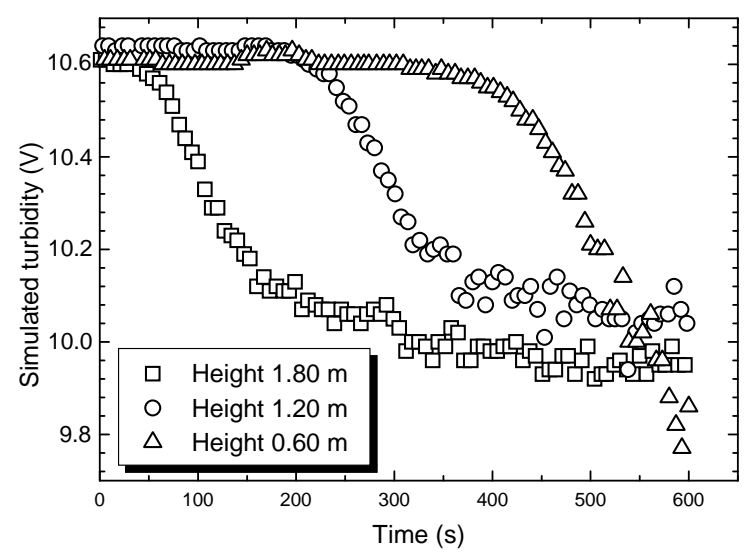

Fig. (6). Results of the batch settling data acquisition for the flocculated sludge. 


\section{CONCLUSION}

This work shows the possibility and the interest of the automation applied to the batch-settling tests of flocculated sludge. The preparation of good quality of sludge is a determinant stage in the study of the flocculated particles sedimentation. The PAC and the aluminum sulphate are the two principal reagents, directly affecting the water parameters in the clarification process. The conception and adaptation of infra-red sensors intended to provide a simple data acquisition system for the sedimentation in the column (experimental device), is the essential part of this work. The large number of data (one data per second) carried out with the developed sensor, makes a clear description of flocculated sludge sedimentation. However, in order to avoid the sensor fooling and to make best correlation between transmission and backscattering of the infra-red beam with the concentrations and the size of the suspended particles, which are the two robustness determining factors of this system, more work will be carried out for further publication.

\section{ACKNOWLEDGEMENTS}

The authors would like to acknowledge Mr. Heinicke J. Professor at the University of Greifswald (Germany) for his help in the data acquisition system. Also Mr. Ali H. Al-Taiar Professor at the University of Sciences and Techniques of Oran (Algeria) is thanked for the English corrections.

\section{REFERENCES}

[1] Yasuhisa A, Yoshikazu T. Settling velocity of an aluminiumkaolinite Floc. Water Res 1997; 31(3): 449-54.
[2] Diehl S. Estimation of the batch-settling flux function for an ideal suspension from only two experiments. Chem Eng J 2007; 62: 4589-601.

[3] Dolgonosov BM. Kinetics of sedimentation of a coagulating suspension. Theor Found Chem Eng J 2005; 39: 635-42.

[4] Je CH, Chang S. Simple approach to estimate flocculent settling velocity in a dilute suspension. Environ Geol 2004; 45: 1002-9.

[5] Viollier E, Michard G, Sarazin G, Choquier A, Rezere G, Trameson P. Une sonde photométrique pour analyse in situ : Principe, méthodes, premiers essais. Rev Sci Eau 1993; 6: 395- 407

[6] Wren DG, Kuhnle RA. Surrogate techniques for suspendedsediment measurements. Proceedings of the Turbidity and Other Sediment Surrogates Workshop, 30-2 April-May 2002; Reno NV, USA.

[7] Urrutlkoetxea A, Garcia-Heras JL. Infrared sensor for suspended solids measurement in the activated sludge process. Sens Actuators A 1993; 37-38: 618-26.

[8] Le Marechal A. Relations entre caractéristiques de la pollution particulaire et paramètres optiques dans les eaux résiduaires urbaines. Doctoral thesis. National Polytechnic Institute of Lorraine, Nancy, France 2003.

[9] Kurt N. A study of channelling behaviour in batch sedimentation. $\mathrm{Ph} . \mathrm{D}$. thesis. School of Civil and Chemical Engineering, RMIT University, England 2006.

[10] Scott F, Lamoureux A. A sediment accumulation sensor for use in lacustrine and marine sedimentation studies. Geomorphology 2005; 68: $17-23$

[11] Bergougnoux L, Firpo JL, Misguich-Ripault J. Optical fiber sensor for measuring high particle concentrations. Powder Technol 1999; 105: 413-7.

[12] Bellino I, Bergougnoux L, Misguich-Ripault J, Firpo JL. Particle size effects on an optical fiber sensor response. Powder Technol 2001; 115: 68-74.

[13] Rodier J. L'analyse de l'eau. Dunod: Paris France 1996.

[14] Kacha S, Derriche Z, Elmaleh S. Equilibrium and kinetics of color removal from dye solutions with bentonite and polyaluminum hydroxide. Water Environ Res 2003; 75(1): 15-21.

(C) Benouali et al.; Licensee Bentham Open.

This is an open access article licensed under the terms of the Creative Commons Attribution Non-Commercial License (http://creativecommons.org/licenses/by-nc/3.0/) which permits unrestricted, non-commercial use, distribution and reproduction in any medium, provided the work is properly cited. 